\title{
High-Frequency Fatigue Behavior of Woven-Fiber-Fabric-Reinforced Polymer-Derived Ceramic-Matrix Composites
}

\author{
Nikhilesh Chawla, ${ }^{*}, \dagger$ Yahya K. Tur, ${ }^{\ddagger}$ John W. Holmes,,${ }^{*} \neq$ and James R. Barber ${ }^{\ddagger}$ \\ Ceramic Composites Research Laboratory, University of Michigan, Ann Arbor, Michigan 48109
}

Andy Szweda*

Advanced Ceramics Division, Dow Corning Corporation, Midland, Michigan 48686

\begin{abstract}
The monotonic and high-frequency $(100 \mathrm{~Hz})$ fatigue behavior of two Nicalon-fabric-reinforced SiCON matrix composites was investigated at room temperature. The matrix composition was varied by the addition of $\mathrm{BN}$ and $\mathrm{SiC}$ particulate fillers, to contain shrinkage from processing by polymer infiltration and pyrolysis (PIP). The composites had strong fiber/matrix bonding, which resulted in substantially less frictional heating than observed with weakly bonded composites. Both composites exhibited fatigue runout at $10^{7}$ cycles at $\sim 80 \%$ of the monotonic strength. Comparison with existing fatigue data in the literature (for the same composites) at $1 \mathrm{~Hz}$ shows no change in fatigue life; i.e., no frequency effect was observed. Most of the stiffness reduction in the composites occurred in the first fatigue cycle, whereas subsequent decreases in moduli were attributed to limited fiber cracking. The major driving force for failure was the localized debonding of transverse and longitudinal plies at the crossover points in the fabric, which, when linked, resulted in interlaminar damage and failure in the composite.
\end{abstract}

\section{Introduction}

$I^{2}$ $\mathrm{N}$ MANY potential applications such as turbine engines and gas heat exchangers, continuous-fiber-reinforced ceramicmatrix composites (CFCMCs) will encounter cyclic-fatigue loading at high frequencies $\left(75 \mathrm{~Hz}\right.$ or higher). ${ }^{1-4}$ Although most of the work in the area of fatigue of CFCMCs has concentrated on low-frequency behavior, ${ }^{5-7}$ it has been shown that high frequencies can exacerbate the accumulation of damage during the cycling of these composites.

In CFCMCs with weak bonding between the fibers and the matrix, energy dissipation via frictional sliding occurs during cyclic loading. ${ }^{8}$ This energy dissipation may result in a substantial temperature increase in the composite, because of the repeated frictional sliding between the fiber and the matrix at the fiber/matrix interface. Thus, the temperature increase in the composite can be used as a damage parameter and, by relating the amount of temperature increase to a given damage state, one can predict when a given specimen will fail.

F. W. Zok-contributing editor

\footnotetext{
Manuscript No. 191808. Received May 20, 1996; approved January 14, 1997. Supported by the U.S. Air Force Office of Scientific Research (AFOSR), under Contract No. F49620-95-1-0206, and the National Science Foundation (NSF), under Contract No. DMR-9257557.

Contract No. DMR-9257557.
Presented at the 20th Annual Conference on Ceramics and Composites, Cocoa Beach, FL, Jan. 1996.

${ }^{*}$ Member, American Ceramic Society.

†Department of Materials Science and Engineering, University of Michigan.

*Department of Mechanical Engineering and Applied Mechanics, University of Michigan.
}

Temperature increases during fatigue have also been observed in thermoplastic-polymer-matrix composites, although, in polymers, the viscoelastic nature of the matrix is the primary mechanism responsible for heating. ${ }^{9}$ The temperature associated with frictional sliding in CFCMCs has been documented in hot-pressed Nicalon ${ }^{\mathrm{TM}}$ (Nippon Carbon Co., Tokyo, Japan)/CAS II composites and chemical-vapor-infiltrated $\mathrm{C} / \mathrm{SiC} \cdot{ }^{10,11}$ At a frequency of $85 \mathrm{~Hz}$ and an $R$ ratio $\left(\sigma_{\min } / \sigma_{\max }\right)$ of 0.04 in $\mathrm{C} / \mathrm{SiC}$, a temperature increase of $50 \mathrm{~K}$ was observed. Large temperature increases have also been observed by Koch and Grathwohl ${ }^{12}$ in $100 \mathrm{~Hz}$ fatigue of Tyranno/C/SiC composites.

The effect of loading frequency on the high-frequency fatigue behavior of a Nicalon/CAS II glass-matrix composite showed that, unlike monolithic ceramics, fatigue life of this composite decreased rapidly as the loading frequency increased. ${ }^{13}$ During fatigue, wear occurs along debonded fiber/matrix interfaces. By lubricating the interface, it was shown that dramatic increases in the fatigue life of this composite system could be obtained. ${ }^{14}$ It is believed that, by producing a damage-tolerant CFCMC with strong fiber/matrix bonding, fatigue properties can be enhanced, because of inhibition of fiber/matrix sliding.

The emphasis of processing research in the ceramic-matrix composite (CMC) area has increasingly shifted from hightemperature and high-cost fabrication techniques to lowertemperature and less-expensive processing techniques to obtain small amounts of residual porosity. Polymer infiltration and pyrolysis (PIP) is an attractive processing route, because of its relatively low cost. Moreover, this approach allows near-netshape molding and fabrication technology that is able to produce almost fully dense composites. ${ }^{15-18}$ In PIP, the fibers are infiltrated with an organic polymer. The polymer is heated to fairly high temperatures $\left(700^{\circ}-900^{\circ} \mathrm{C}\right)$ and pyrolyzed to form a ceramic matrix. Because of the relatively low yield of polymer to ceramic, several infiltrations are used to densify the composite. A large amount of shrinkage and cracking in the matrix occurs during the pyrolysis process; particulate fillers are added to the polymer to reduce shrinkage and to stiffen the matrix material in the composite. ${ }^{19}$

In this study, the fatigue behavior of an eight-harness satinweave Nicalon-fiber-reinforced SiCON matrix composite made by PIP was investigated. Two matrix variations were tested: one composite had a BN filler and the other had a SiC filler. The fibers were coated with a proprietary boroncontaining coating that created a strong bond between the fibers and the matrix. A debond stress of $\sim 1500 \mathrm{MPa}$ was obtained from fiber push-out tests. ${ }^{20}$ This value is considerably higher than that observed for conventional $\mathrm{SiC} / \mathrm{SiC}$ materials with a carbon interface. Contrary to the widespread belief that a weak fiber/matrix interface is needed for optimum monotonic and fatigue properties in CMCs, it will be shown that the strong interface in Nicalon/SiCON composites can provide both high monotonic toughness and excellent fatigue life. 
Table I. Density and Percent Porosity of Nicalon/SiCON Matrix Composites

\begin{tabular}{ccc}
\hline Composite & Density $\left(\mathrm{g} / \mathrm{cm}^{3}\right)$ & Open porosity $(\%)$ \\
\hline Nicalon/SiCON, BN filler & 2.107 & 5.17 \\
Nicalon/SiCON, SiC filler & 2.215 & 5.08 \\
\hline
\end{tabular}

The monotonic and high-frequency fatigue behavior was investigated at room temperature. The temperature increase in the test specimens, because of frictional heating, and the stiffness reduction during the fatigue tests were monitored to characterize the damage state of the composite. Scanning electron microscopy (SEM) was used to identify microstructural damage that occurred during fatigue.

\section{Experimental Procedure}

As mentioned in the introduction, the Nicalon/SiCON composites were processed by using PIP. The woven eight-harness satin-fiber fabric was coated with a proprietary boroncontaining interface, stacked, and infiltrated. The volume fraction of fibers in the composite was nominally $50 \%$. The composites were infiltrated with a mixture of polymer and filler particles during the first infiltration, whereas nine or ten subsequent infiltrations were made with polymer only. One composite had $20 \% \mathrm{BN}$ particles in the matrix, whereas the second composite had $40 \% \mathrm{SiC}$ particles. The polymer-pyrolyzed amorphous ceramic matrix consisted of a mixture of silicon, carbon, nitrogen, and oxygen.

Porosity was measured by using the Archimedes method (water displacement). Typically, in large parts made by PIP, the outside of the material is well infiltrated and, thus, has less porosity than the inside or the bulk of the material. In this study, however, reinfiltration has been conducted on the tensile bars themselves, so infiltration is homogenous throughout the specimen, because of smaller dimensions, especially the thickness of the specimen. Table I shows the density and percent porosity of the $\mathrm{BN}$ - and $\mathrm{SiC}$-filler composites.

Testing was conducted using a high-frequency servohydraulic load frame (MTS Systems, Eden Prairie, MN). Alignment of the load train was conducted by the specifications delineated in the provisional ASTM standard for the monotonic tensile testing of continuous-fiber-reinforced ceramic-matrix composites. ${ }^{21}$ At a load of $1 \mathrm{kN}$ (equivalent to $<500$ microstrain), the amount of bending in the specimen was $<5 \%$ of the tensile uniaxial strain. Experiments were conducted at a minimum stress of $10 \mathrm{MPa}$ and a loading frequency of $100 \mathrm{~Hz}(100$ cycles per second). A water-cooled chamber was used to maintain a constant temperature around the specimen during the experiments. Temperature measurements of the specimen were conducted using an infrared pyrometer, and a highfrequency extensometer was used to measure strain. The edge-loaded specimens were machined using conventional diamond tooling to a length of $111 \mathrm{~mm}$, with a gauge length of 33 $\mathrm{mm}$. Details of the testing and gripping procedures are given elsewhere. ${ }^{10,11,13,14}$

Specimen gauge sections were polished and surface replicas were taken at intermediate points of the test, in an attempt to observe any progression in damage. The fatigue test was stopped and the replica was taken at intermediate and/or maximum loads, because, at the minimum load, any potential matrix cracks could close. The specimen was also removed from the grip periodically and the gauge section was examined via SEM.

\section{Results and Discussion}

\section{(1) As-Received Microstructure of the Composites}

Filler composition profoundly affected the degree of processing-related cracking in the matrix. The matrix with $\mathrm{BN}$ filler was relatively crack free, compared to the matrix with $\mathrm{SiC}$ filler, as shown in Fig. 1. However, the addition of $\mathrm{SiC}$ to the matrix was not as effective in containing shrinkage during pyrolysis, which resulted in cracks through fiber bundles, as shown in Fig. 1(b). The filler network obtained during fillercontrolled pyrolysis, which has been described in the introduction, was observed in the microstructure of both composites (Fig. 2).

\section{(2) Monotonic Tensile Behavior}

Figure 3 shows monotonic tensile curves for the two composites. The composite with $\mathrm{BN}$ filler had a higher strength;
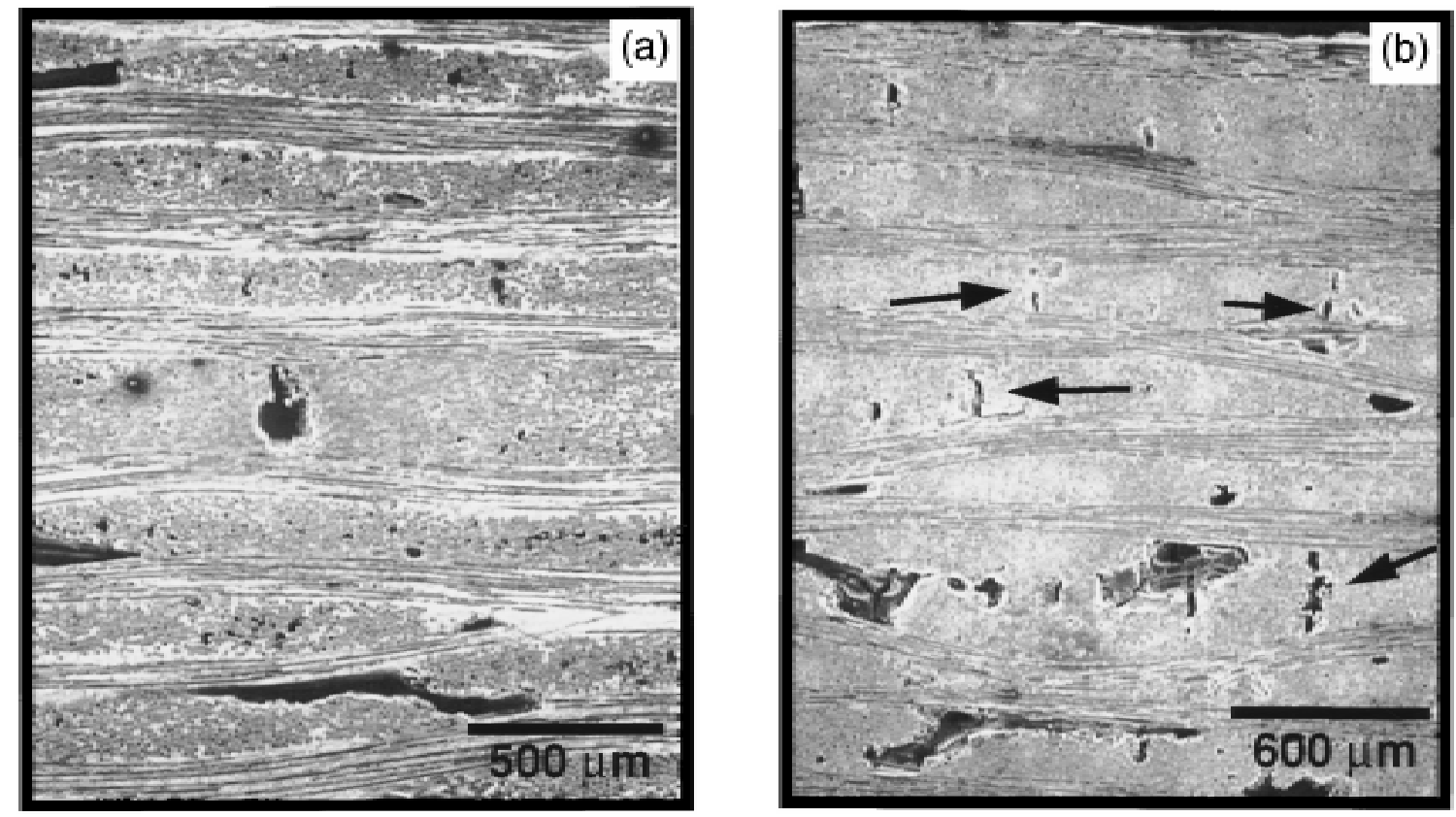

Fig. 1. As-received microstructure of the composites with (a) BN filler, which was relatively crack free, and (b) SiC filler, which is not as effective in containing shrinkage during pyrolysis, resulting in cracks through the fiber bundles. 


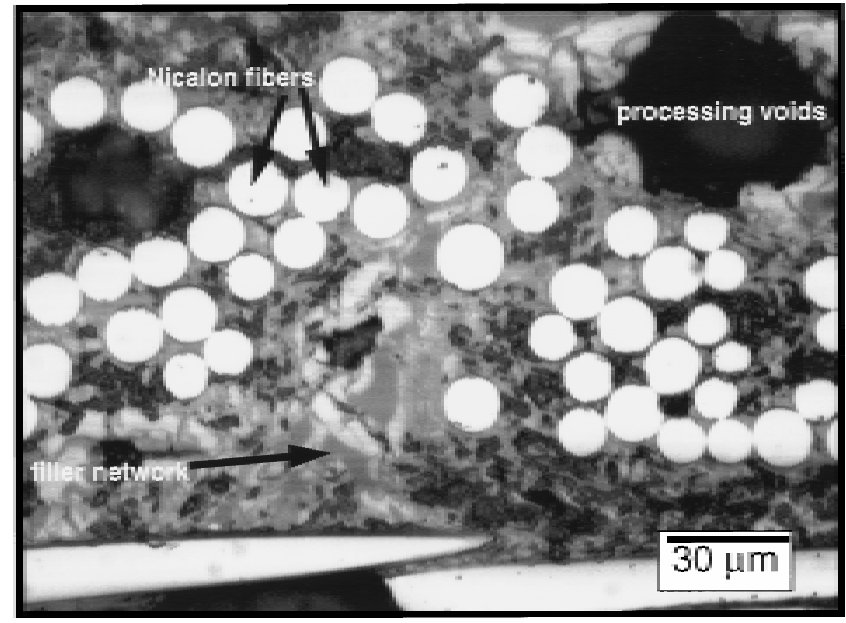

Fig. 2. Optical micrograph of filler network obtained during fillercontrolled pyrolysis in $\mathrm{BN}$ - and $\mathrm{SiC}$-filler composites.

however, in the linearly elastic region of the material, a lower stiffness was observed, compared to that of the composite with the $\mathrm{SiC}$ filler. Clearly, the addition of the $\mathrm{SiC}$ filler increased the modulus of the matrix and, therefore, the modulus of the composite was also increased. Although the reinforcement volume fraction and architecture in both composites was the same, the SiC composite had a lower strength. An explanation for this behavior is provided in Section III(4) ("Damage Mechanisms").

Because the fiber was very strongly bonded to the matrix, the well-documented mechanisms of matrix cracking, followed by fiber debonding and crack deflection and finally fiber pullout, did not apply in these composites. Instead, because of the woven nature of this material, the occurrence of a distinct proportional limit in the monotonic curves was attributed to localized matrix cracking and debonding between longitudinal and transverse fiber bundles at the crossover points in the woven fabric. More credence can be given to this mechanism because tests on unidirectional composites in the same matrix show linear stress-strain behavior to failure with little strain at fracture. $^{22}$ Thus, a strong interface, coupled with the woven nature of the fiber architecture, can lead to high strain to failure and high strength of these composites. The precise nature of these mechanisms is described in the next section, which addresses fatigue behavior.

\section{(3) Fatigue Life}

The stress-cycles $(S-N)$ curves for the composites are shown in Fig. 4. At high cycles $\left(\geq 10^{5}\right)$, a clustering of failures in the two materials was observed; i.e., the fatigue lives of the two materials in the high-cycle regime were approximately the same. Slightly below the monotonic strength (e.g., $20 \mathrm{MPa}$ below the ultimate tensile strength $\left.\left(\sigma_{\text {uts }}\right)\right)$, the fatigue life of the composite was $\sim 10^{4}$ cycles.

Both composites show fatigue runout at $10^{7}$ cycles at a stress of $200 \mathrm{MPa}$, which is close to $80 \%$ of the monotonic tensile strength. This high value for the fatigue limit is comparable to that of Nicalon/SiC materials with a carbon interface..$^{4,12,23,24}$ However, the magnitude of the tensile strength of Nicalon/SiC materials is only $\sim 160-200 \mathrm{MPa}$, compared to $300-350 \mathrm{MPa}$ for Nicalon/SiCON composites.

Lara-Curzio et al. ${ }^{25}$ studied the Nicalon/SiCON composite with $\mathrm{SiC}$ filler at lower frequencies $(1 \mathrm{~Hz})$ and, because of a longer test duration at $1 \mathrm{~Hz}$, determined that no failures at $10^{6}$ cycles was a satisfactory endurance limit. In this study, endurance limits of the composite were measured at $10^{7}$ cycles; however, failures were observed at fatigue lives as high as $7 \times$ $10^{6}$ cycles. The $S-N$ curve obtained in this study is very similar to that of Lara-Curzio et al. ${ }^{25}$ which indicates that there is no significant effect of frequency on the fatigue life of this composite. One reason for this phenomenon may be the strong interfacial bonding between the fiber and the matrix, such that fiber/matrix wear during fatigue is inhibited. In composites with a weak fiber/matrix bond, wear rates at the interface are much faster at higher frequencies, which results in more premature failures. Because there seems to be no effect of frequency in this composite system, testing at higher frequencies is a more attractive way of testing the composite for higher lifetimes in a shorter amount of time.

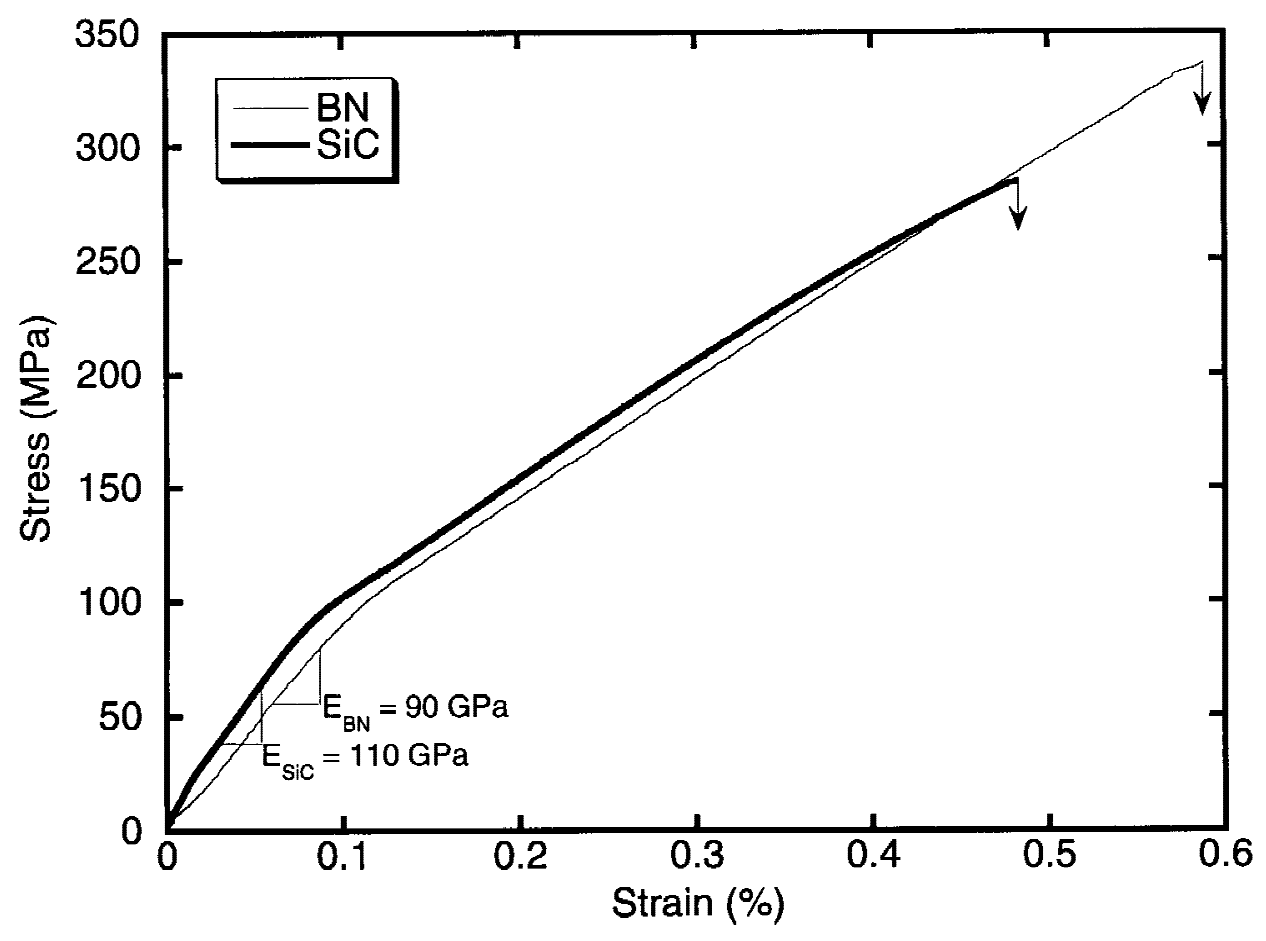

Fig. 3. Monotonic tensile curves for BN- and SiC-filler composites. 


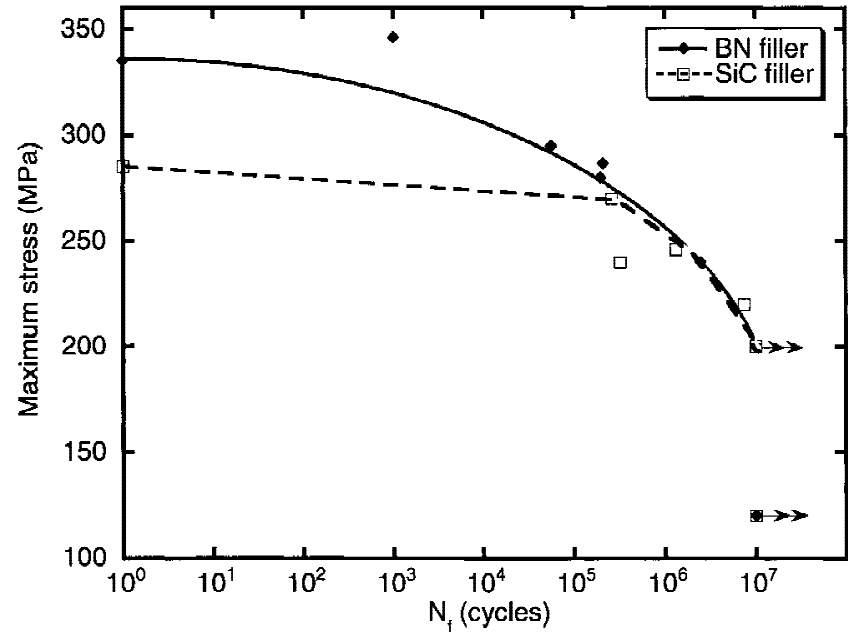

Fig. 4. Stress-cycles $(S-N)$ curve for the composites tested in fatigue at a frequency of $100 \mathrm{~Hz}$.

\section{(4) Damage Mechanisms}

Unlike most unidirectional and woven CMCs with weak fiber/matrix interfaces, transverse cracks were not observed during cycling. These observations were taken based on surface replicas as well as SEM examination of the gauge length of the specimen of the composite.

To explain the damage mechanisms, we must first examine the strong interfacial bond between the fiber and the matrix in this composite system. Because of the strong nature of bonding, any matrix microcracks are either arrested by fibers or propagate through the fibers, without debonding or crack deflection at the fiber/matrix interface. However, fiber cracking will only occur if stresses are high enough for fiber fracture, and, because of the soft nature of the matrix, cracks will not necessarily propagate in a catastrophic fashion. Furthermore, matrix cracks may also be deflected by the particulate filler in the matrix before reaching the fiber/matrix interface.

A decrease in the tangent modulus may be attributed to debonding of the longitudinal and transverse bundles, which results in debonding of the plies. The wavy parts of the bundles are prone to debonding, because of strain mismatch between plies. Several studies of two-dimensional fiber-fabricreinforced polymer-matrix composites have documented similar mechanisms. ${ }^{26-28}$ These weave crossover regions may debond if the stresses exceed the bond strength between bundles. With a higher applied stress, it is likely that the debonded region increases. Figure 5 shows severe cracking of a transverse bundle that crosses over a longitudinal bundle in a failed specimen that was fatigued. These observations were

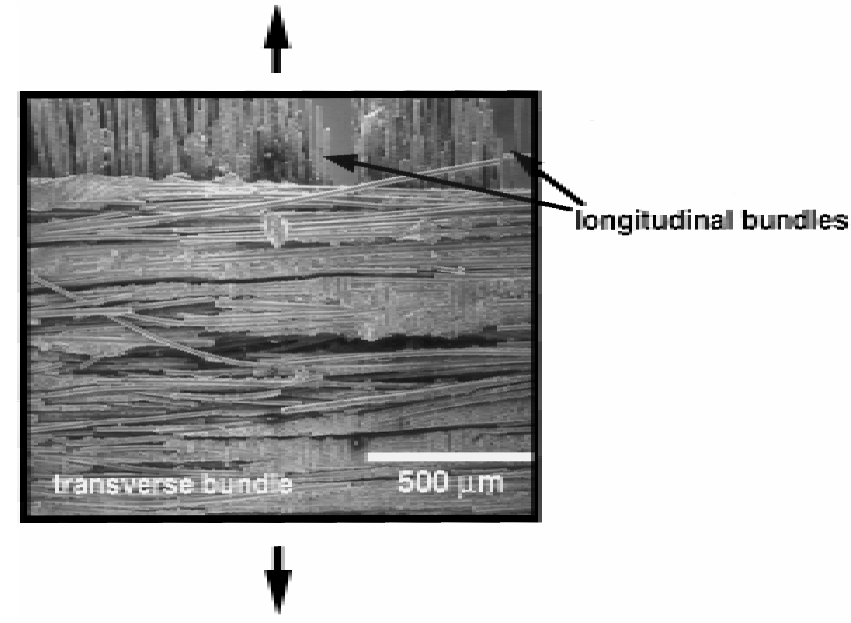

Fig. 5. Severe cracking of a transverse bundle that crosses over a longitudinal bundle in a specimen that was fatigued.

taken from a failed specimen, because they could not be observed during the test.

Thus, the damage evolution process is envisioned to occur as follows. Because of strain mismatches between transverse and longitudinal bundles, matrix microcracking occurs at the contact points between the two types of bundles. This damage occurs at low stresses, with pronounced damage occurring at the proportional limit stress. Stress relief in the transverse bundle may also occur through the formation of microscopic matrix cracks or cracks that emanate from processing pores.

In the composite with the BN filler, with an increase in damage, the localized debonded sites and cracks resulted in interlaminar cracking and failure, as shown in Fig. 6. Interlaminar failure during compressive fatigue in woven $\mathrm{CFCMCs}$ has also been reported in $\mathrm{C} / \mathrm{SiC}$ composites. ${ }^{29,30}$

\section{(5) Stress-Strain Hysteresis and Modulus Reduction}

From stress-strain hysteresis measurements and modulus reduction data, it was determined that the majority of damage in the composite during fatigue occurred during initial loading. Damage was quantified by defining a normalized damage parameter $D_{\mathrm{E}}$, which is given by 5,31

$$
D_{\mathrm{E}}=1-\frac{E}{E_{0}}
$$

were $E_{0}$ is the initial modulus, taken from the linearly elastic portion of the loading curve, and $E$ is the modulus at a given number of cycles. Figure 7 shows that, in both composites, the

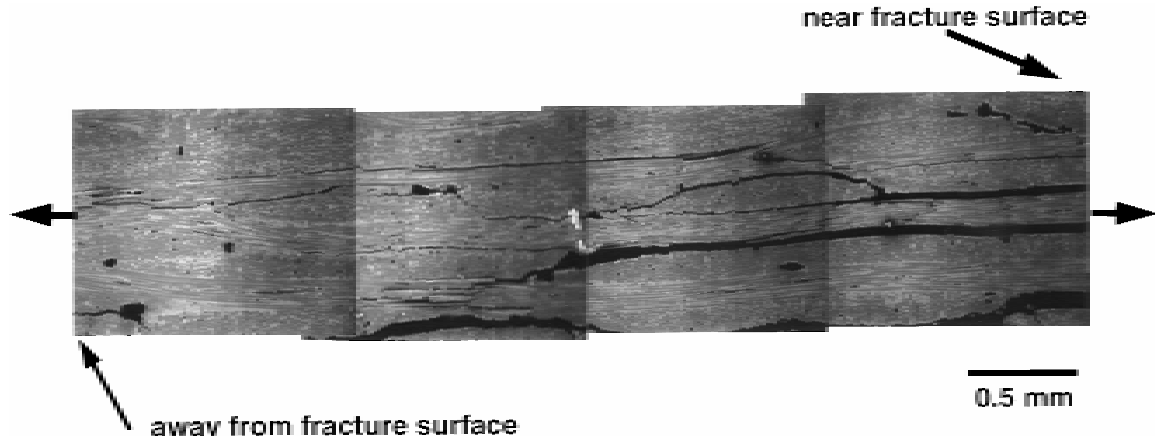

Fig. 6. SEM micrograph of interlaminar cracking and failure during fatigue, resulting from the linkage of localized debonded sites at crossover points between longitudinal and transverse bundles. 


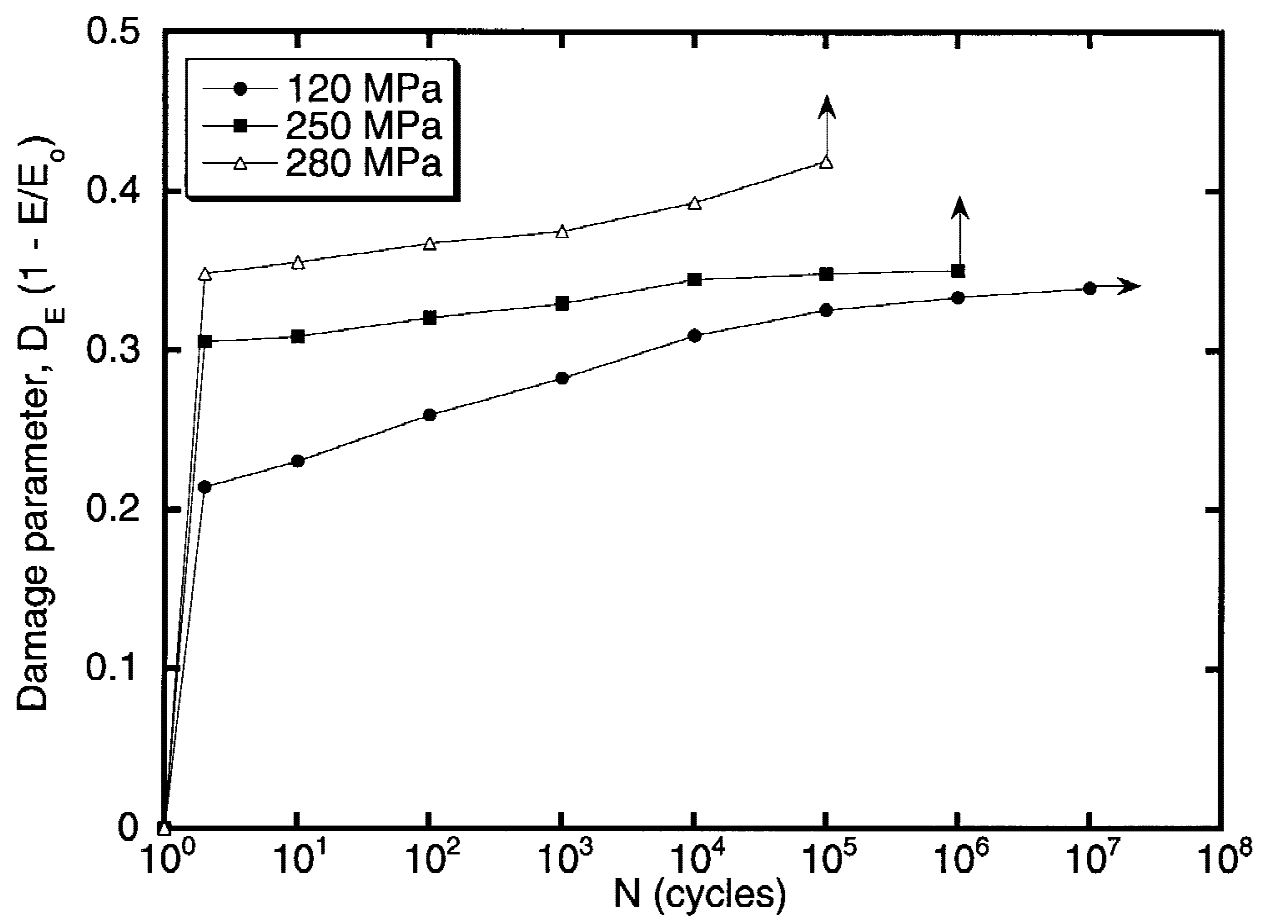

(a)

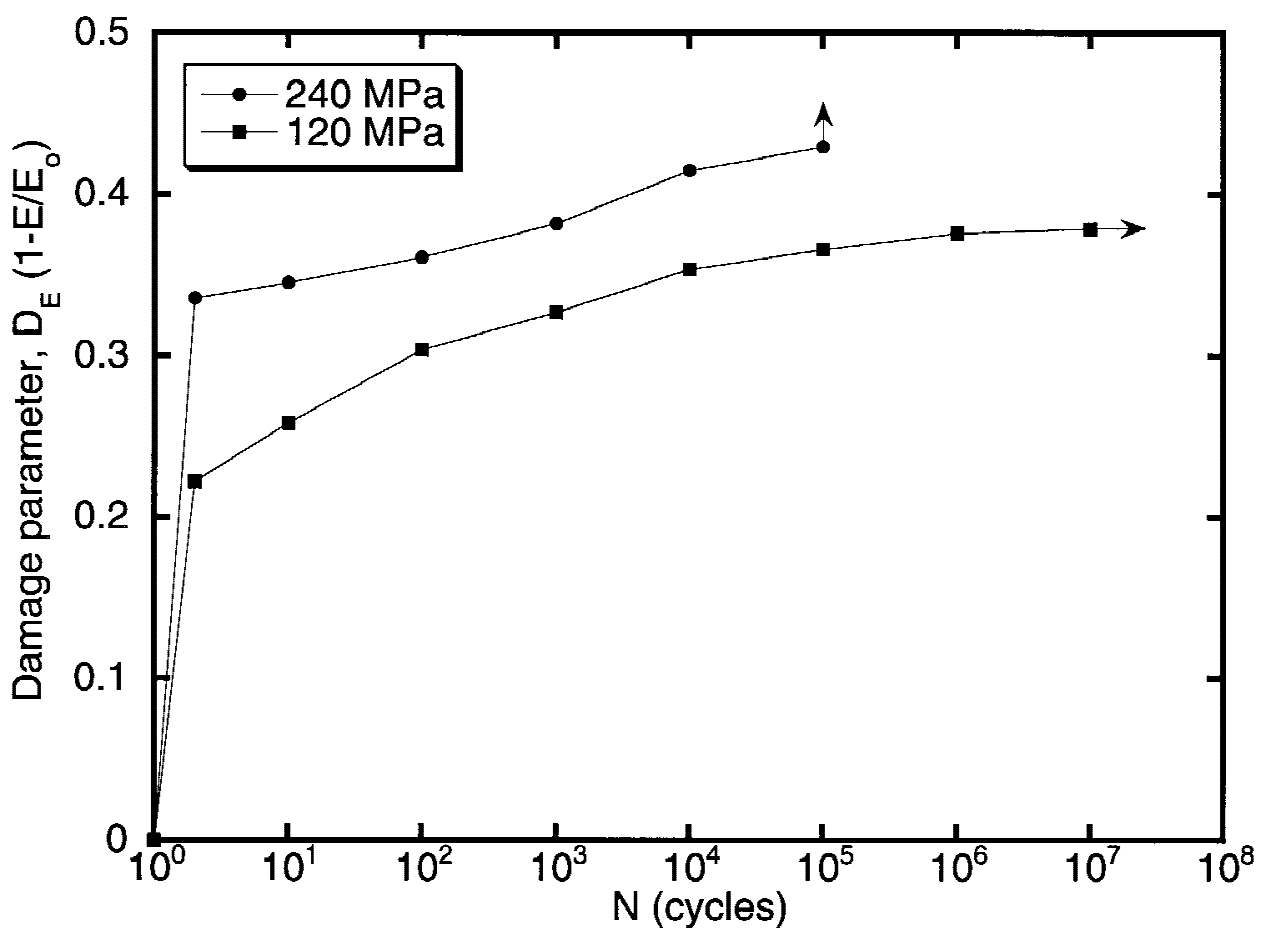

(b)

Fig. 7. Damage versus cycles in (a) the BN-filler composite and (b) the SiC-filler composite. In both composites, the majority of damage occurred in the first cycle.

majority of damage occurred in the first cycle. A similar observation has been reported for $1 \mathrm{~Hz}$ fatigue of the same composite system. ${ }^{17}$ The higher the initial loading stress (also the cycling stress), the higher the degree of damage. Subsequent cyclic damage after the first cycle was rather limited. At a stress level slightly above the proportional limit, the modulus decrease after the first cycle was more gradual, attaining a saturation point at $\sim 10^{6}$ cycles.
The irreversible damage that occurred in the first cycle or loading ramp can be attributed to debonding and microcracking at crossing points of longitudinal and transverse bundles, as described previously. This damage mechanism is in distinct contrast with the fatigue behavior of unidirectional Nicalon/CAS, for example, where the fiber/matrix bonding is quite weak (debond stress of $\sim 400 \mathrm{MPa}$ and an interfacial sliding stress $(\tau)$ of $8-10 \mathrm{MPa}){ }^{32}$ Hysteresis loops in the latter 
system show an $\mathrm{S}$-shaped behavior, ${ }^{8,33}$ which is characterized by changes in the interfacial shear stress at the fiber/matrix interface during loading and unloading. Furthermore, in Nicalon/CAS, an increase in the modulus is observed at high cycles; this increase is attributed to an increase in the interfacial shear stress. In the present system, no S-shape has been observed in the hysteresis loops and the amount of permanent strain is negligible, which leads us to believe that fiber sliding is not a factor (Fig. 8). Rather, the relative motion of bundles in the weave would seem to be responsible for the hysteresis, and the "soft" nature of the matrix contributes to very little residual strain on unloading.

\section{(6) Frictional Heating Behavior}

A significant increase in temperature in both composites was observed during high-frequency fatigue. A transient stage was observed, where the specimen began to heat up until an equilibrium was achieved with the surrounding environment. When the specimen reaches an equilibrium temperature, any increase in temperature can be attributed to incremental damage. As shown in Fig. 9, the transient stage is almost instantaneous. This stage is followed by a region where the temperature remains fairly constant, which indicates a plateau in the damage level of the composite. In the last portion of the fatigue life of the composite, an increase in temperature is observed, followed by failure. The length of the plateau region is highly dependent on the applied stress. At $120 \mathrm{MPa}$, the plateau region continues until fatigue runout of the material. At $240 \mathrm{MPa}$, the plateau region is longer than that at $280 \mathrm{MPa}$, where it is almost absent (i.e., the temperature exhibits a continuous increase from the onset of equilibrium). Thus, in addition to providing a quantitative estimate of the energy dissipation in the composite, the temperature increase can be used as a damage parameter.

Heating seems to have resulted from laminate and ply delamination and the accompanying friction between two surfaces during fatigue. When debonding between the bundles occurs, frictional slip between the fiber bundles at the crossover points in the weave is responsible for slight increases in the specimen temperature. This mechanism, which results in limited heating, is currently under investigation. Limited fiber fracture all seems to occur during fatigue, after very localized matrix cracking. The SEM micrographs in Fig. 10, taken from a specimen of an interrupted fatigue test, show localized matrix cracks that have propagated through the fibers.

The degree of debonding between the bundles was dependent on the applied stress. If the stress level was high enough, most of the bundle debonding occurred in the first cycle, as shown by the large increase in the damage parameter $D_{\mathrm{E}}$ (Fig. 7). At stresses close to the proportional limit, the damage accumulation was more gradual, which indicates possible progressive debonding of the fiber bundles until the rate of damage accumulation became increasingly small.

It is instructive to once again compare the behavior of Nicalon/SiCON with that of unidirectional Nicalon/CAS with a weak fiber/matrix interface. ${ }^{10}$ In the latter system, the magnitude of heating is quite large, because of frictional sliding at the fiber/matrix interface, where a large number of small-diameter fibers are allowed to slide and dissipate heat during fatigue. Also, a bell-shaped temperature curve is observed. ${ }^{10,13,14}$ This curve is attributed to easy slip in the beginning of fatigue (lower $\tau$ ) and higher temperature increase, followed by restricted slip in the latter parts of the test (higher $\tau$ ) and lower temperature increase. In the present study, fiber sliding is not a significant damage mechanism. Preliminary fiber pushout studies in virgin and fatigued specimens show little changes in debond stress and interfacial sliding stress. ${ }^{20}$

\section{(7) Residual Strength}

Samples that survived $10^{7}$ cycles at $200 \mathrm{MPa}$ were tested monotonically to determine the effect of fatigue on the residual strength of the composite. The behavior of the composites also provided some insight into the damage mechanisms in the composite during fatigue.

Figure 11 shows the strength of the virgin material and residual strength of the $\mathrm{BN}$ filler composite after fatigue. The fatigued specimen had a very small amount of accumulated strain and the ultimate strength of the composite was higher than that of the virgin material. Furthermore, the stress-strain curve for the fatigued specimen was linear, up to the applied maximum fatigue stress. The increase in strength is similar to

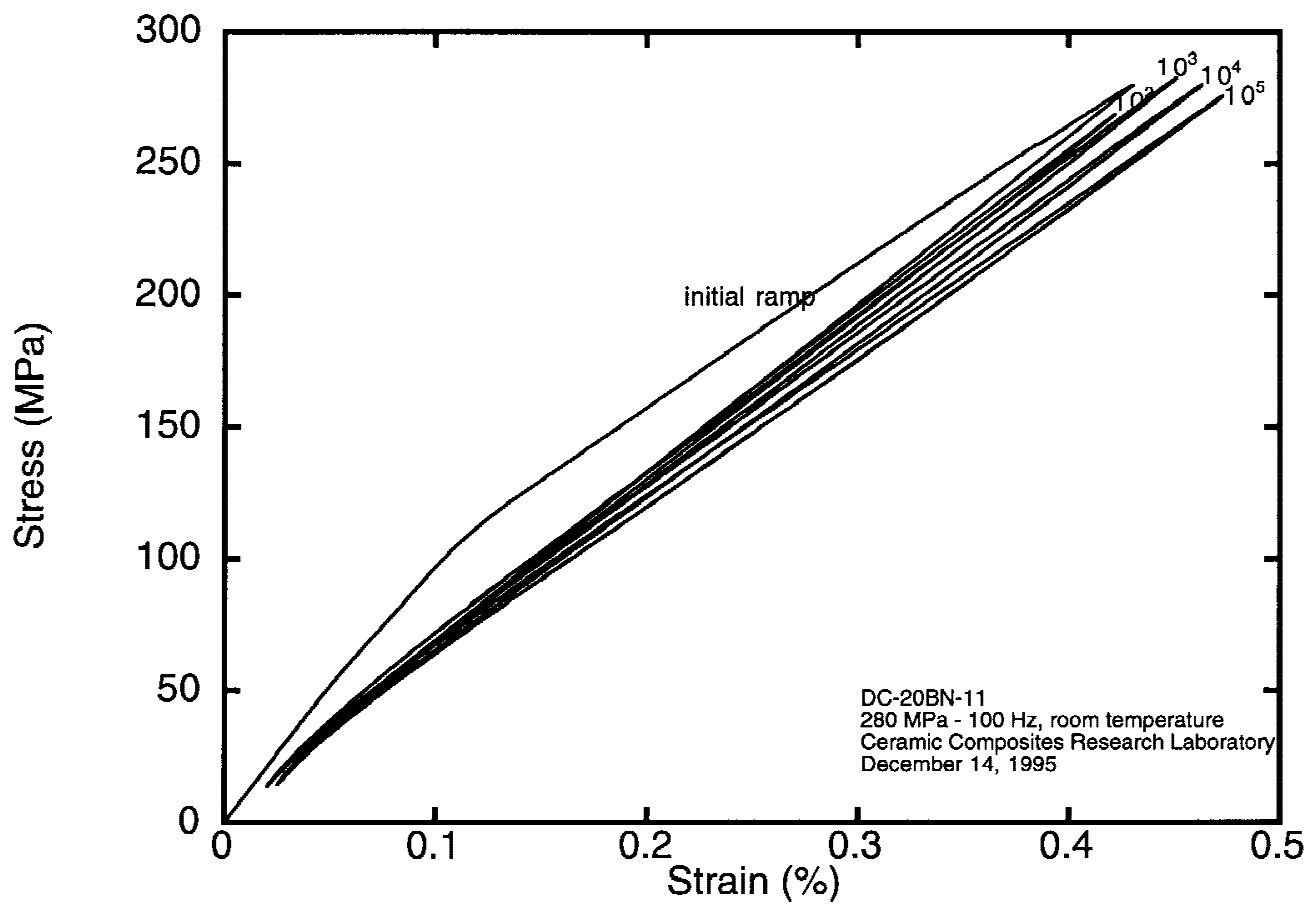

Fig. 8. Stress-strain hysteresis in Nicalon/SiCON with $\mathrm{BN}$ filler. Note the absence of an S-shaped loop (normally associated with fiber sliding) and a negligible amount of permanent strain. 


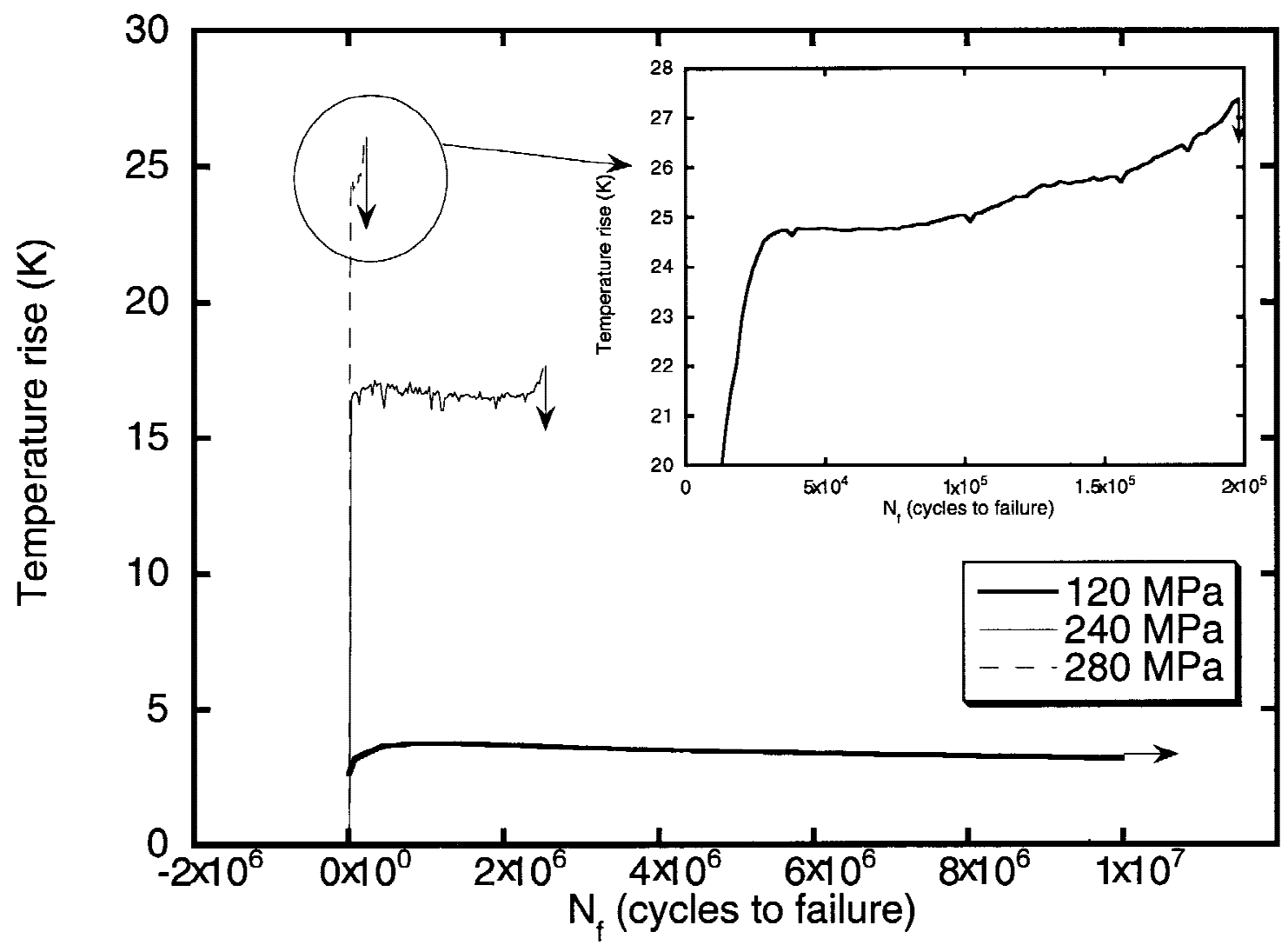

(a)

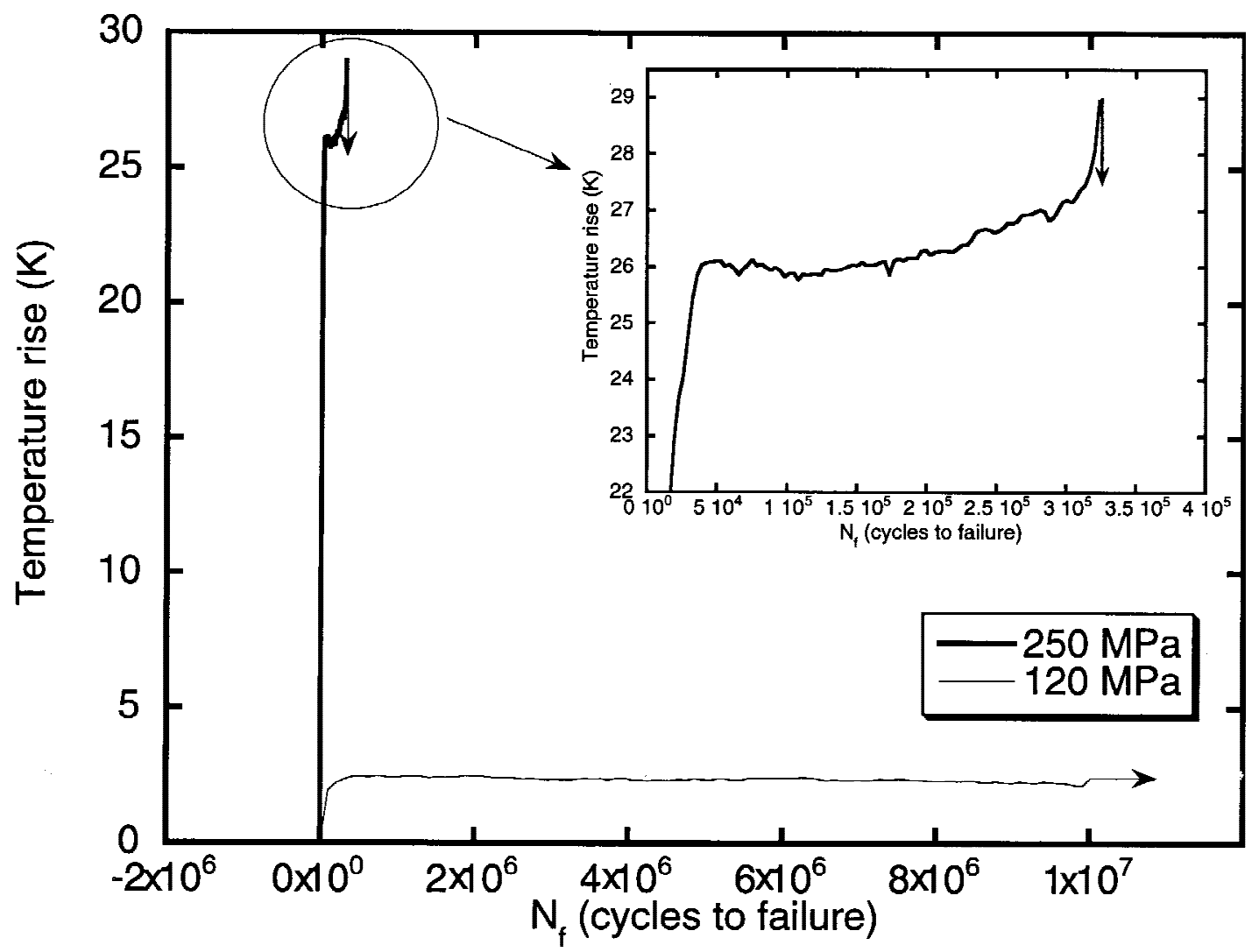

(b)

Fig. 9. Temperature increase versus cycles in (a) the BN-filler composite and (b) the SiC-filler composite; a slight increase in temperature with increasing cycles was observed after stabilization, which continued to increase until failure of the composite occurred. 

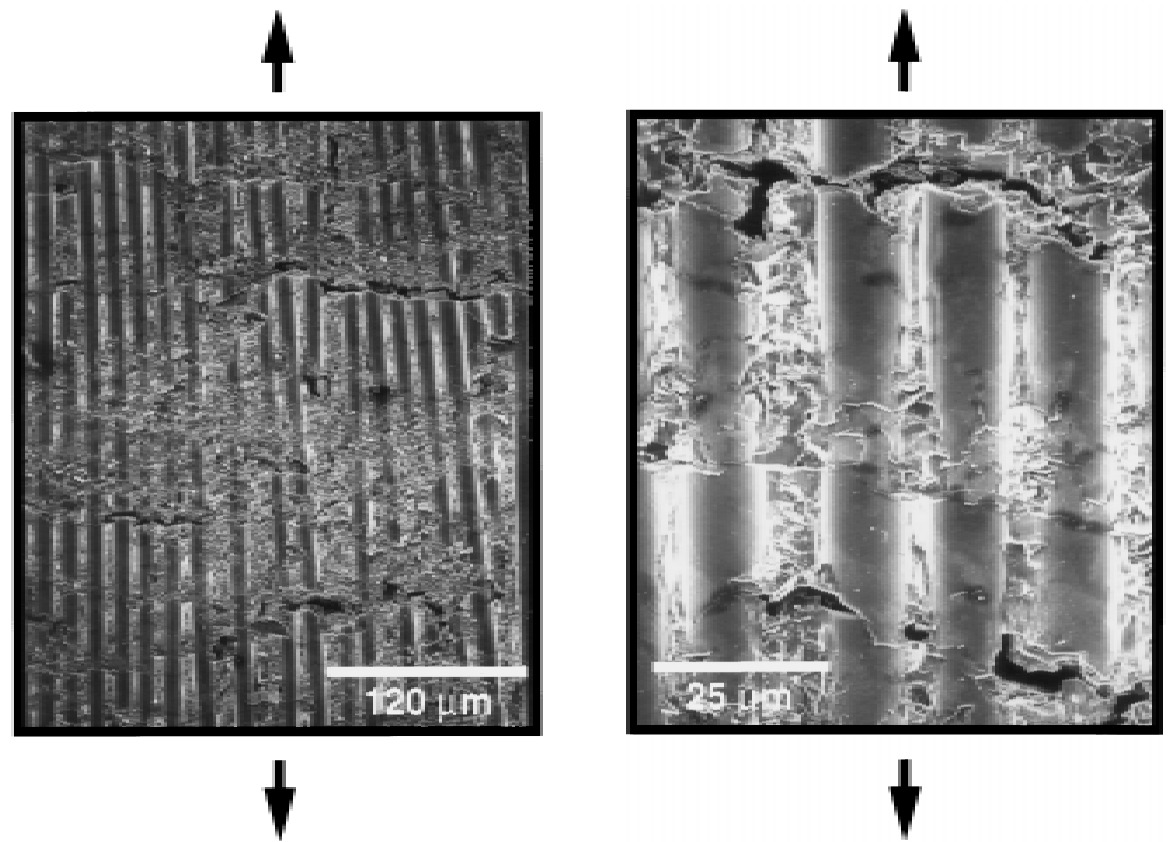

Fig. 10. SEM micrographs of localized fiber fracture from a specimen taken from an interrupted fatigue test.

that observed in a woven $\mathrm{C} / \mathrm{SiC}$ composite that was investigated by Shuler et al. ${ }^{11}$ As described previously, the mechanism responsible for higher strength after fatigue in Nicalon/ $\mathrm{SiCON}$ is the alignment of the weave during fatigue. Figure 12 is a schematic of a variation of a mechanism proposed by Shuler et $a l .{ }^{11}$ that shows weave alignment and straightening mechanisms that occur during fatigue of the woven composite. The matrix with BN filler was very compliant, unlike the $\mathrm{SiC}$ matrix in the work by Shuler et al. ${ }^{11}$ Because the BN-filler matrix is not a conventionally brittle ceramic matrix, weavestretching and aligning mechanisms can easily occur, with the relief of strain mismatches allowing longitudinal bundles to stretch while the transverse bundles align themselves. A higher strain to failure was achieved with stretching of the weave; i.e., because fatigue damage likely redistributes and reduces the severity of localized stresses in the composite, more-uniform loading of the bundles can occur.

In the SiC-filler composite, the residual strength of the composite after fatigue was approximately the same as that of the virgin material (Fig. 13). Because of the stiffer nature of SiCfilled matrix, the fatigue process did not reduce or redistribute localized stresses in the composite. This phenomenon is demonstrated further by the fracture surface in the SiC-filler composite, which shows planar fracture with no sign of interlami-

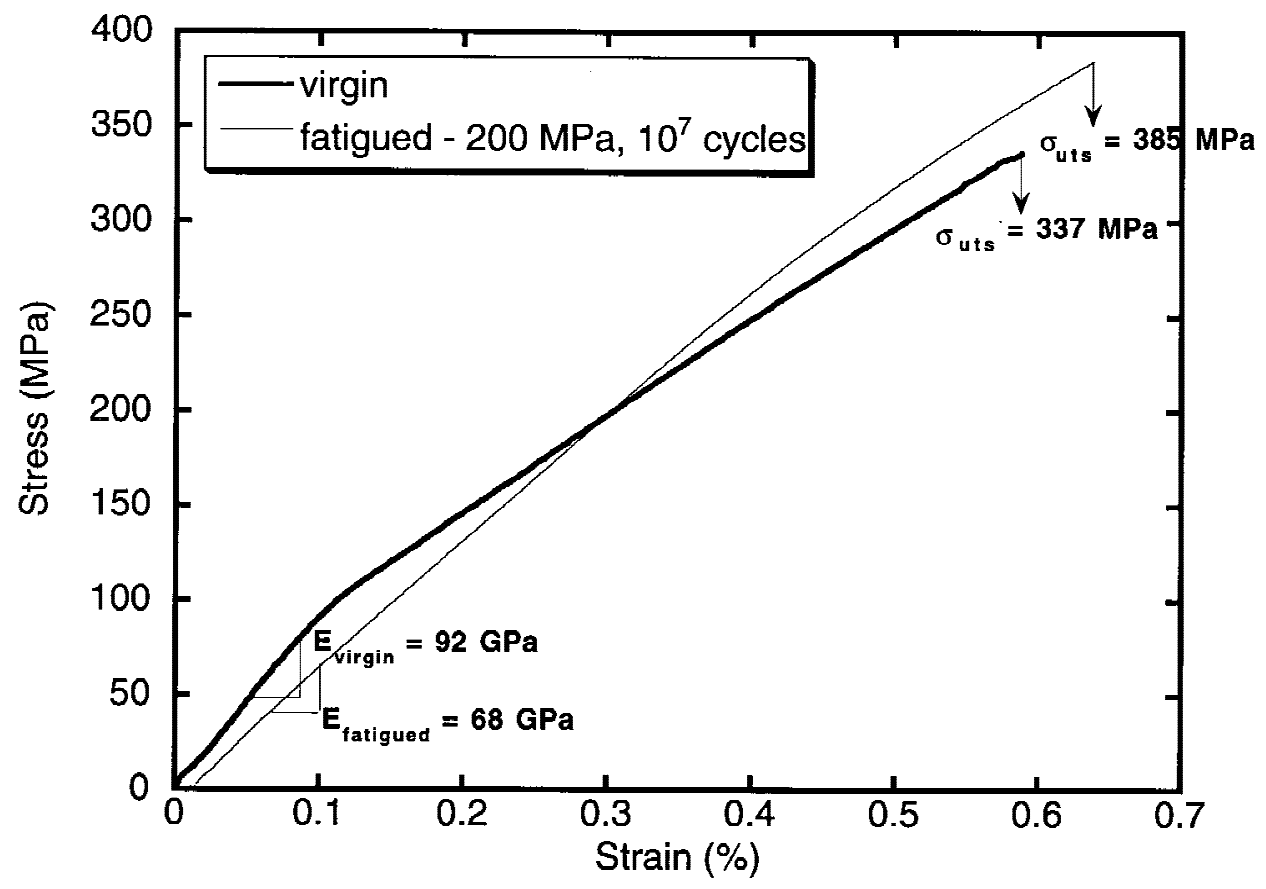

Fig. 11. Residual strength after fatigue versus virgin material strength in the BN-filler composite; the BN-filler composite has higher strength, because of the straightening and aligning processes of the fiber fabric during the fatigue process. 

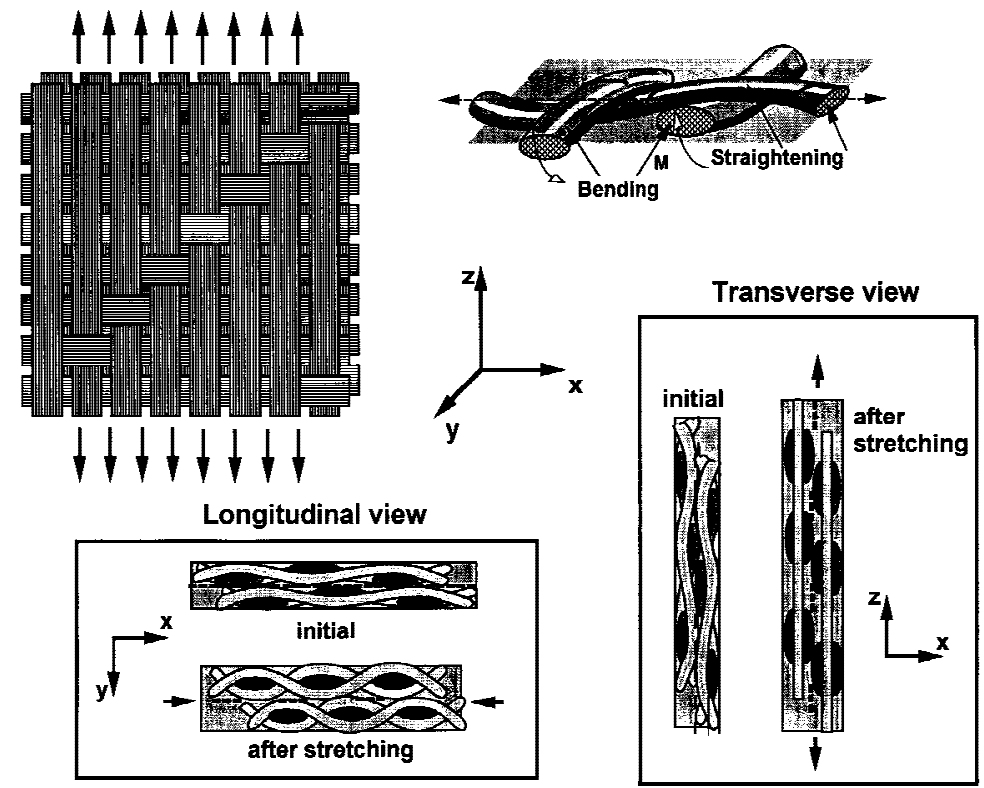

Fig. 12. Schematic of the stretching of the weave and realignment of transverse fiber bundles, which occurs during fatigue of Nicalon/SiCON with a BN filler.

nar shear (Fig. 14). Because fiber fracture likely did not occur at a fatigue stress of $200 \mathrm{MPa}$, the strength of the $\mathrm{SiC}$ composite remained the same as that of the virgin material.

\section{Conclusions}

Several conclusions were obtained from this study of the high-frequency fatigue behavior of Nicalon/SiCON matrix composites:

(1) A strong interface between the fiber and the matrix hinders interfacial sliding and the amount of frictional heating during fatigue. Because interface sliding was not a factor in this composite system, frequency does not seem to have a role in the fatigue life of the composite.

(2) Microstructural observations indicated that damage during fatigue occurred between crossover points of longitudinal and transverse fiber bundles, which are postulated to occur due to strain mismatches between the bundles. By debonding these sites and relieving the stress concentrations, alignment of the weave occurred in the BN-filler composite, which resulted in higher post-fatigue strengths in that composite.

(3) Because fatigue did not redistribute or reduce any localized stresses in the SiC-filler composite, weave-stretching mechanisms were thought to be inhibited; thus, no increase in strength after fatigue was observed.

(4) The largest amount of damage during fatigue occurred during the first cycle, especially at or above the proportional limit of the composite, where the bulk of transverse-longitudinal ply debonding occurred.

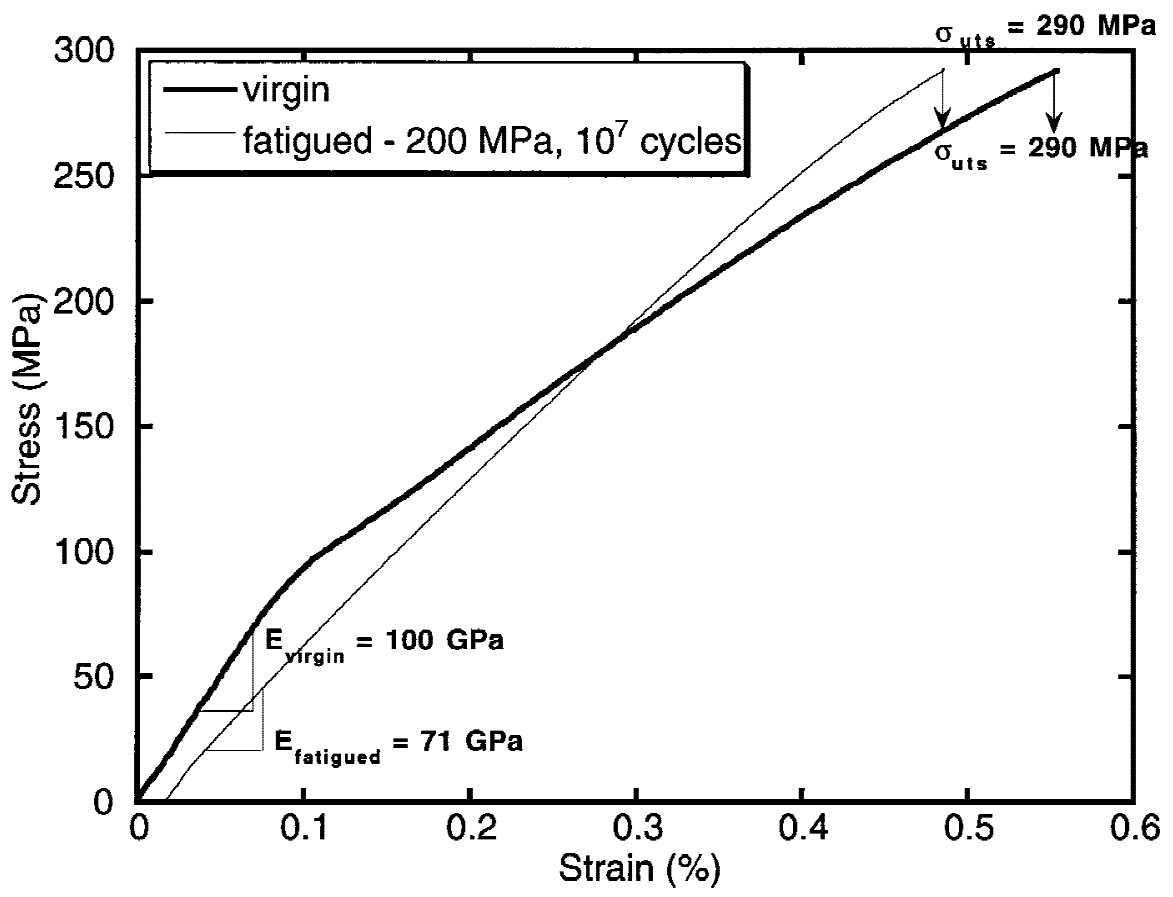

Fig. 13. Residual strength after fatigue versus virgin material strength in the SiC-filler composite. Strengths between fatigued and virgin materials are similar because of the absence of weave-aligning processes. 

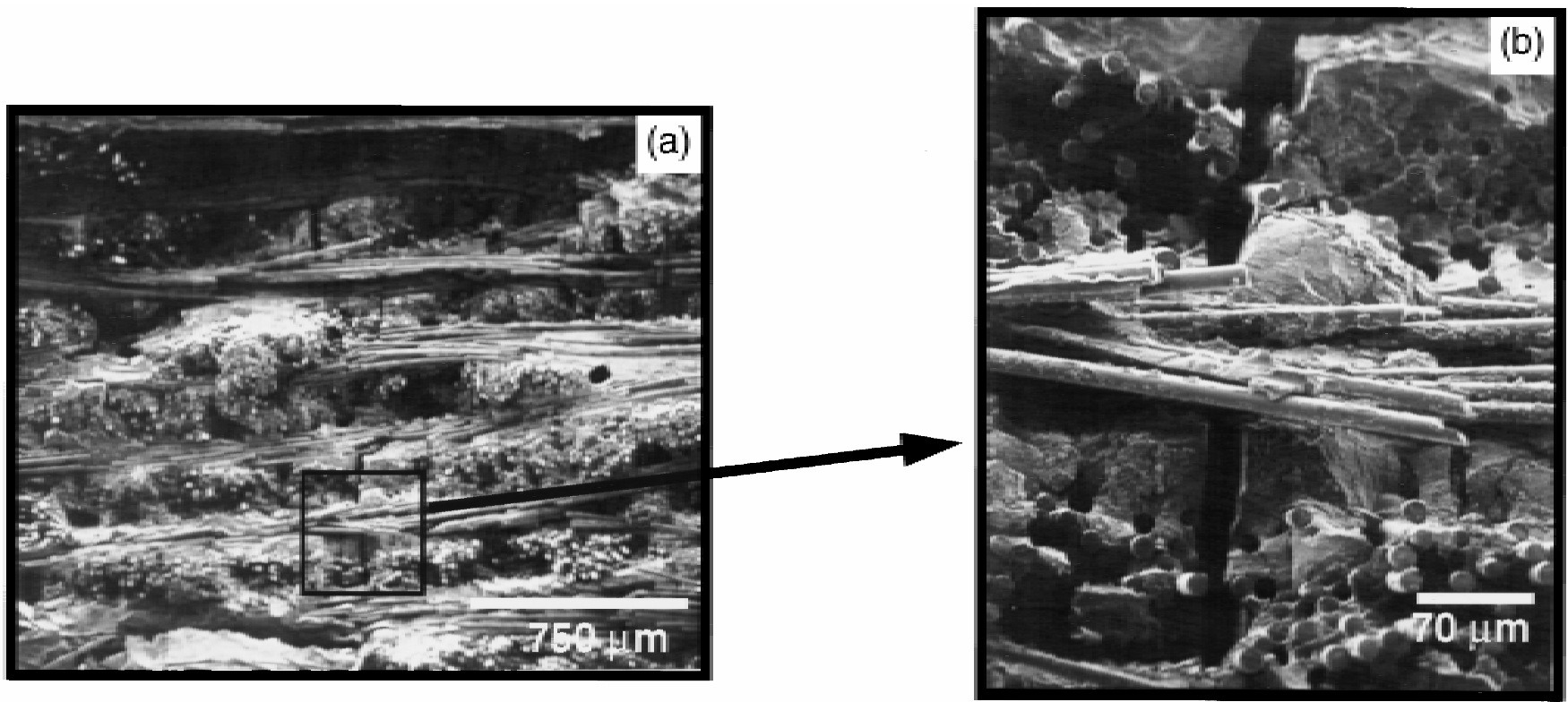

Fig. 14. (a) Fracture surface of the SiC-filler composite, showing planar fracture with little pullout. The higher stiffness of the matrix does not allow the localized stresses to be redistributed; thus, the weave is not allowed to stretch and interlaminar damage is not observed. (b) Highermagnification micrograph, showing cracks from processing.

\section{References}

${ }^{1}$ J. W. Holmes and B. F. Sorensen, "Fatigue Behavior of Continuous FiberReinforced Ceramic Matrix Composites"; p. 261 in High Temperature Mechanical Behavior of Ceramic Composites. Edited by S. V. Nair and K. Jakus. Butterworth-Heinemann, Boston, MA, 1995.

${ }^{2}$ S. Richlen, "Applications of Fiber-Reinforced Ceramic Matrix Composites"; pp. 495-526 in Handbook on Continuous Fiber-Reinforced Ceramic Matrix Composites. Edited by R. L. Lehman, S. K. El-Rahaiby, and J. B. Wachtman Jr. American Ceramic Society, Westerville, OH, 1996

${ }^{3}$ R. Kochendörfer and W. Krenkel, "CMC Intake Ramp for Hypersonic Propulsion Systems"; pp. 13-22 in Ceramic Transactions, Vol. 57, HighTemperature Ceramic-Matrix Composites I: Design, Durability, and Performance. Edited by A. G. Evans and R. Naslain. American Ceramic Society, Westerville, OH, 1995.

${ }^{4}$ D. Rouby and P. Reynaud, "Fatigue Behavior Related to Interface Modification during Load Cycling in Ceramic-Matrix Fibre Composites," Compos. Sci. Technol., 48, 109-18 (1993).

${ }^{5}$ P. Karandikar and T.-W. Chou, "Damage Development and Moduli Reductions in Nicalon-Calcium Aluminosilicate Composites under Static Fatigue and Cyclic Fatigue,"' J. Am. Ceram. Soc., 76 [7] 1720-28 (1993).

${ }^{6}$ L. P. Zawada, L. M. Butkus, and G. A. Hartman, "Tensile and Fatigue Behavior of Silicon Carbide Fiber-Reinforced Aluminosilicate Glass," J. Am. Ceram. Soc., 74 [11] 2851-58 (1991).

${ }^{7}$ N. Chawla, P. K. Liaw, E. Lara-Curzio, R. A. Lowden, and M. K. Ferber, "Effect of Fiber Fabric Orientation on the Mechanical Behavior of Continuous Fiber Ceramic Composites"; p. 291 in High Performance Composites-Commonalty of Phenomena, Proceedings of The Minerals, Metals, and Materials Society (Rosemont, IL, Oct. 1994). Edited by K. K. Chawla, P. K. Liaw, and S. G. Fishman. The Metallurgical Society (TMS), Warrendale, PA, 1994.

${ }^{8}$ T. Kotil, J. W. Holmes, and M. Comninou, "Origin of Hysteresis Observed During Fatigue of Ceramic-Matrix Composites," J. Am. Ceram. Soc., 73 [7] 1879-83 (1990).

${ }^{9}$ E. Dan-Jumbo, S. G. Zhou, and C. T. Sun, "Load-Frequency Effect on Fatigue Life of IMP6/APC-2 Thermoplastic Composite Laminates"; p. 113 in Advances in Thermoplastic Composite Materials, ASTM Special Technical Publication 1044. Edited by G. M. Newaz. American Society for Testing Materials, Philadelphia, PA, 1989.

${ }^{10} \mathrm{~J}$. W. Holmes and C. Cho, "Experimental Observations of Frictional Heating in Fiber-Reinforced Ceramics," J. Am. Ceram. Soc., 75 [4] 929-38 (1992).

${ }^{11}$ S. F. Shuler, J. W. Holmes, X. Wu, and D. Roach, "Influence of Loading Frequency of the Room-Temperature Fatigue of a Carbon-Fiber/SiC-Matrix Composite," J. Am. Ceram. Soc., 76 [9] 2327-36 (1993).

${ }^{12} \mathrm{D}$. Koch and G. Grathwohl, "Tensile Fatigue Testing of SiC-SiC Composites"; p. 217 in Composites Testing and Standardization ECCM-CTS. EACM, Bordeaux, France, 1992.

${ }^{13}$ J. W. Holmes, X. Wu, and B. F. Sørensen, "Frequency Dependence of Fatigue Life and Internal Heating of a Fiber-Reinforced/Ceramic-Matrix Composite,", J. Am. Ceram. Soc., 77 [12] 3284-86 (1994).

${ }^{14}$ B. F. Sorensen and J. W. Holmes, "Improvement in the Fatigue Life of Fiber-Reinforced Ceramic by Use of Interfacial Lubrication," Scr. Metall. Mater., 32, 1393 (1995).

${ }^{15}$ R. Lundberg, R. Pompe, R. Carlsson, and P. Goursat, "Fibre Reinforced Silicon Nitride Composites," Compos. Sci. Technol., 37, 165-76 (1990).
${ }^{16}$ F. Sirieix, P. Goursat, A. Lemcote, and A. Dauger, "Pyrolysis of Polysilazanes: Relationship between Precursor Architecture and Ceramic Microstructure," Compos. Sci. Technol., 37, 7-19 (1990).

${ }^{17}$ K. Sato, H. Morozumi, A. Tezuka, O. Funayama, and T. Isoda, "Interface and Mechanical Properties of Ceramic Fiber Reinforced Silicon Nitride Composites Prepared by a Preceramic Polymer Impregnation Method"; pp. 199-204 in Ceramic Transactions, Vol. 58, High Temperature Ceramic-Matrix Composites II: Manufacturing and Materials Development. Edited by A. G. Evans and R. Naslain. American Ceramic Society, Westerville, OH, 1995.

${ }^{18}$ M. F. Gonon, G. Fantozzi, M. Murat, and J. P. Disson, "Association of the CVI Process and of the Use of Polysilazane Precursor for the Elaboration of Ceramic Matrix Composites Reinforced by Continuous Fibres," J. Eur. Ceram. Soc., 15, 185-90 (1995)

${ }^{19}$ P. Greil, "Active-Filler-Controlled Pyrolysis of Preceramic Polymers," $J$ Am. Ceram. Soc., 78 [4] 835-48 (1995).

${ }^{20} \mathrm{~J}$. I. Eldridge, N. Chawla, and J. W. Holmes; unpublished work.

1" ASTM Standard for Monotonic Tensile Strength Testing of Continuous Fiber Advanced Ceramics with Solid Rectangular Cross-Section Specimens at Elevated Temperatures," ASTM Subcommittee C28.07 on Ceramic Matrix Composites, Rev. 1.5, American Society for Testing and Materials, Philadelphia, PA, June 1994.

${ }^{22}$ R. Boisvert and A. Szweda; unpublished work.

${ }^{23}$ P. Reynaud, "Cyclic Fatigue of Ceramic-Matrix Composites at Ambient and Elevated Temperatures," Compos. Sci. Technol., 56, 809-14 (1996).

${ }^{24}$ N. Chawla, J. W. Holmes, and R. A Lowden, "The Role of Interfacial Coatings on the High Frequency Fatigue Behavior of Nicalon/C/SiC Composites," Scr. Mater., 35, 1411 (1996).

${ }^{25}$ E. Lara-Curzio, M. K. Ferber, R. Boisvert, and A. Szweda, "The High Temperature Tensile Fatigue Behavior of a Polymer-Derived Ceramic Matrix Composite," Ceram. Eng. Sci. Proc., 16 [4] 341-49 (1995).

${ }^{26} \mathrm{P}$. T. Curtis, "The Fatigue Behaviour of Fibrous Composite Materials," $J$ Strain Anal., 24, 235 (1989).

${ }^{27}$ P. T. Curtis and S. M. Bishop, "An Assessment of the Potential of Woven Fibre-Reinforced Plastics for High Performance Applications," Composites, 15, 259 (1984)

${ }^{28}$ T. Fujii, S. Amijima, and K. Okubo, "Microscopic Fatigue Processes in a Plain-Weave Glass-Fibre Composite," Compos. Sci. Technol., 49, 327-33 (1993).

${ }^{29}$ Z. G. Wang, C. Laird, Z. Hashin, B. W. Rosen, and C.-F. Yen, "Mechanical Behaviour of a Cross-Weave Ceramic Matrix Composite-Part I, Tensile and Compressive Loading," J. Mater. Sci., 26, 4751-58 (1991).

${ }^{30}$ Z. G. Wang, C. Laird, Z. Hashin, B. W. Rosen, and C.-F. Yen, "The Mechanical Behaviour of a Cross-Weave Ceramic Matrix Composite-Part II, Repeated Loading," J. Mater. Sci., 26, 5335-41 (1991).

${ }^{31}$ Z. R. Xu, K. K. Chawla, A. Wolfenden, A. Neuman, G. M. Liggett, and N. Chawla, "Stiffness Loss and Density Decrease due to Thermal Cycling in an Alumina Fiber/Magnesium Alloy Composite," Mater. Sci. Eng. A, A203, 75-80 (1995).

${ }^{32}$ E. Lara-Curzio and M. K. Ferber, "A Methodology for the Determination of the Interfacial Properties of Brittle Matrix Composites," J. Mater. Sci., 29, 6152 (1994).

${ }^{33}$ D. Koch and G. Grathwohl, " $S$-Curve Behavior and Temperature Increase of Ceramic-Matrix Composites During Fatigue Testing"; see Ref. 3, pp. 41924. 